\title{
Feto Maternal Outcome in Second versus First Stage Caesarean Delivery in a Tertiary Rural Medical College
}

\author{
Dr. Swapan Das ${ }^{1}$, Dr. Sunit Kumar Sarkar ${ }^{2}$ \\ 1. Asst. Professor, Deptt. of Obstetrics and Gynaecology, Bankura Sammilani Medical College, Bankura West \\ Bengal, India. \\ 2. PGT, Deptt. of Obstetrics and Gynaecology, Bankura Sammilani Medical College, Bankura West Bengal, \\ India
}

\begin{abstract}
Objective: We performed a hospital based cohort study to compare neonatal and maternal outcomes of the primary caesarean section performed in first stage versus second stage of labour.

Methods: At least 100 cases underwent caesarean delivery in the second stage of labour were taken. For each case two consecutive cases underwent caesarean delivery during the first stage of labour were taken as control for the study. Primary maternal outcomes of interest were uterine atonia, transfusion requirements, urinary system injury and requirement for uterine artery/ hypogastric artery ligation.

Results: Urinary injury, transfusion requirement, uterine atonia and requirement for uterine artery or hypogastric artery ligation were significantly more frequent in women who underwent caesarean section in the second stage of labour compare to women undergoing caesarean delivery in the first stage of labour.

Conclusion: Caesarean section in the second stage of labour is associated with increased maternal and neonatal morbidities. Special attention is required to the patients undergoing caesarean section in the second stage of labour.
\end{abstract}

Key words: Caesarean Section, Second Stage of Labour, First Stage of Labour.

\section{Introduction}

Caesarean Section is the most commonly performed abdominal operation in women all over the world. Variable rates of caesarean section is reported between and within countries [1-3]. Recent data suggest that caesarean delivery is in labour is associated with increased maternal morbidity compared with caesarean delivery with no labour [4]. One fourth of the primary caesarean section are reported to be performed in the second stage of labour [5-6] and are more complicated compared to the ones performed in the first stage. The second stage of labour can be defined as the time elapsed from full dilatation of the cervix to expulsion of the faetus. Caesarean section at full dilatation of cervix with an impacted featal head can be technically difficult and associated with increased trauma to the lower uterine segment and adjacent structures as well as increased haemorrhage and infection [7]. Neonatal mortality and morbidity due to hypoxia and featal trauma remains to be one of the major issue regarding the caesarean section performed in the second stage of labour [6-8] .

Although the morbidity of caesarean delivery in the second stage of labour has been compared with instrumental vaginal delivery in different studies, the morbidity of second stage versus first stage caesarean delivery is less well studied in our country.

As there is limited study we undertook this hospital based cohort study to compare the maternal and neonatal outcomes of caesarean delivery in second stage of labour versus caesarean delivery in the first stage of labour.

\section{Material and Methods}

The current hospital based cohort study was conducted from $1^{\text {st }}$ July, 2011 to $30^{\text {th }}$ June, 2012 in B.S. Medical College Bankura. Inclusion criteria for the study were nulliparity, faetus with vertex presentation and gestational age older than 36 weeks of gestation and having no maternal comorbid disease or no associated obstetric complications such as preeclampsia and diabetes mellitus. Inform consents were obtained from all patients, and the study was approved by the institutional ethical committee.

At least 100 cases underwent caesarean delivery in the second stage of labour were taken. For each case 2 consecutive case underwent caesarean delivery during the first stage of labour were taken as control for the study. Maternal age, BMI gestational age, augmentation of labour oxytocin were noted preoperatively. Intra operative uterine atonia, transfusion requirement urinary system complication and the requirement of uterine artery or hypogastric artery ligation were also noted. Birth weight, the APGAR score of the new born at the $5^{\text {th }}$ minute, neonatal injury if any and the requirement to transfer the infant to neonatal intensive care unit were the post operative data recorded. 
Numerical variables were compared between groups by student independent samples ' $t$ ' test or Mann Whitenay ' $\mathrm{n}$ ' test as appropriate. Categorical data will be comparing by Chisquare with Yates correction were applicable. All analysis will be two tailed with $\mathrm{P}<0.05$ considers statistically significant.

\section{Results}

Table 1 shows the maternal and perinatal characteristics. In this study 300 patients were taken into consideration among which 100 cases were undergone second stage caesarean section and 200 case undergone first stage caesarean section without any statistical significant difference in the ages of the patient. BMI of the patients undergone second stage caesarean section $[28.1 \pm 4.7]$ were significantly greater than the patients undergone first stage caesarean section [24.1 \pm 3.8$](\mathrm{P}<0.05)$. Gestational ages of the patients were $3.89 \pm 1.06$ and $38.57 \pm 1.29$ in first stage and second stage caesarean section respectively with significantly lower duration of pregnancy in the later group $(\mathrm{P}<0.05)$. The median duration of active phase of labour was significantly longer in women undergoing caesarean section in second stage of labour compared with women having caesarean delivery in the first stage of labour [13.98 \pm 1.26 Vs $11.43 \pm 2.12, \mathrm{P}<0.05]$. The median cervical dilatation at delivery was significantly greater in women undergoing caesarean delivery in the second stage of labour compared with women having caesarean section in the first stage of labour $(10 \mathrm{Vs} 5 \mathrm{~cm}, \mathrm{P}<0.05) .80$ women undergone caesarean section in second stage of labour required induction or augmentation of labour and 160 women undergone caesarean section in the first stage of labour require induction or augmentation. This is statistically not significant. There was no differences in mean birth weight between the two groups.

Table 2 shows intra-operative findings and complications of caesarean section in second and first stage of labour. Nine (9\%) of the women undergoing caesarean section in the second stage of labour had uterine atonia significantly more than the one $(0.5 \%)$ women who underwent caesarean section in the first stage of labour. Atonia and other causes of haemorrhage resulted in a significantly higher blood transfusion requirement in women undergoing caesarean section in the second stage of labour $(9 \%$ Vs. $0.5 \%, \mathrm{P}<0.05)$. Intra operative complication in 16 women $(16 \%)$ in the second stage caesarean section was significantly more frequent compared to the $3(1.5 \%)$ women having caesarean section in the first stage of labour. Uterine / hypogastric artery ligation in the $8(8 \%)$ women in the second stage caesarean section was significantly more frequent compared to the one $(0.5 \%)$ women having caesarean section in the first stage of labour. Urinary system injury was also more frequent in the patience undergoing caesarean section in the second stage of labour $3(3 \%)$ Vs $0(0 \%)$ respectively $(\mathrm{P}<0.05)$.

Table 3 Shows neonatal complications. Incidence of neonatal trauma of the neonates born to mother who had undergone caesarean section in the second stage of labour was more than that of the neonates born to mother in the first stage of labour ( $5 \%$ Vs $0.5 \%, \mathrm{P}<0.05)$. APGAR Score $\leq 3$ at 5 mins was more frequent $(9 \%)$ in the neonates of the mothers operated in the second stage of labour compared to the women operated in the first stage of labour (1\%), however without statistical significance. Twelve of the new born (12\%) born to mothers underwent caesarean section of the second stage of labour were admitted to the neonatal intensive care unit (NICU) compared to 3 (1.5\%) newborns born to mothers underwent caesarean section in the first stage of the labour and the results were statistically significant $(\mathrm{P}<0.05)$.

\section{Discussion}

The present study shows that the caesarean section performed in the second stage of labour have significantly higher maternal and neonatal morbidity. Allen et. al had compared the maternal and neonatal morbidity of the caesarean section in the first and second stage of labour in a similar but retrospective study (9). The maternal morbidities can be due to the difficulty in handling the faetus impacted to the maternal pelvis. The unfavourable neonatal outcomes are probably due to prolonged labour which leads to hypoxia. Previous studies had also shown adverse maternal outcomes when the second stage of labour is longer than the normal (10-13). Similar to our study they have demonstrated an increased risk of perinatal asphyxia. Previous study conducted by Cebekulu and Buchmann in South Africa also concluded that caesarean section in the second stage of labour causes more maternal and neonatal morbidity (14). A multi center study conducted in 13 university centres also revealed that caesarean deliveries in the second stage of labour showed marginally increased maternal but not neonatal morbidity (15).

We have demonstrated in our study that the urinary system injury was increased about three times in the caesarean section performed in the second stage of labour we suggest that the caesarean section in the second stage of labour are technically more difficult. Development of uterine atonia and requirement of uterine or hypogastric artery ligation in the case of severe haemorrhage are also found to be more frequent in caesarean section performed in the second stage of labour and can be due to the longer labour resulting in uterine fatigue. Increased frequency of uterine atonia and emergency uterine or hypogastric artery ligation in patients requiring caesarean section at the second stage of labour seems to be the main cause of increased transfusion requirement in this group.

In conclusion our study suggests that women undergoing caesarean section in the second stage of labour have increased maternal and faetal morbidity and required special care and should be handled and 
operated by experienced obstetricians. The neonatologists should be present in every case of caesarean section performed in the second stage of labour.

TABLE - 1 Maternal and Perinatal Characteristics

\begin{tabular}{|c|c|c|c|}
\hline & $\begin{array}{l}\text { Caesarean section in the second stage } \\
\text { of labour }(\mathrm{n}=100)\end{array}$ & $\begin{array}{l}\text { Caesarean section in the first } \\
\text { stage of labour }(\mathrm{n}=200)\end{array}$ & $\mathrm{P}$ Value \\
\hline Mean maternal age Year (SD) & $22.03[3.47]$ & $21.52[2.98]$ & $\mathrm{NS}$ \\
\hline BMI (SD) & $24.1[3.8]$ & $38.1[4.7]$ & $\mathrm{P}<0.05$ \\
\hline $\begin{array}{c}\text { Mean gestational age at delivery, } \\
\text { week (SD) }\end{array}$ & $38.57[1.29]$ & $11.43[2.12]$ & $\mathrm{P}<0.05$ \\
\hline $\begin{array}{c}\text { Median length of active phase of } \\
\text { labour, hour [SD] }\end{array}$ & $13.98[1.26]$ & $5(3,7)$ & $\mathrm{P}<0.05$ \\
\hline $\begin{array}{c}\text { Median dilatation of cervix at } \\
\text { delivery, cm (25 }\end{array}$, $75^{\text {th }}$ centiles) & $10(10,10)$ & $160(80)$ & $\mathrm{NS}$ \\
\hline $\begin{array}{c}\text { Number requiring induction or } \\
\text { augmentation }(\%)\end{array}$ & $80(80)$ & $2.61(0.39)$ & $\mathrm{NS}$ \\
\hline Mean birth weight Kg (SD) & $2.86(0.39)$ & \\
\hline
\end{tabular}

TABLE - 2 : Intra operative findings and complication of Caesarean section in second and first stage of labour

\begin{tabular}{|c|c|c|c|c|}
\hline & Total No. of & $\begin{array}{l}\text { Caesarean section in the } \\
\text { events }\end{array}$ & $\begin{array}{l}\text { Caesarean section in the } \\
\text { second stage of labour } \\
(\mathrm{n}=100)(\%)\end{array}$ & $\begin{array}{l}\mathrm{P} \text { Value } \\
\text { firstage of labour } \\
(\mathrm{n}=200)(\%)\end{array}$ \\
\hline Blood Transfusion & 10 & $9(9 \%)$ & $1(0.5 \%)$ & $\mathrm{P}<0.05$ \\
\hline Uterine Atonia & 10 & $9(9 \%)$ & $3(0.05 \%)$ & $\mathrm{P}<0.05$ \\
\hline Intra operative complications & 19 & $16(16 \%)$ & $1.5 \%)$ & $\mathrm{P}<0.05$ \\
\hline Wound infection & 9 & $8(8 \%)$ & $1(0.5 \%)$ & $\mathrm{P}<0.05$ \\
\hline $\begin{array}{c}\text { Uterine/ Hypogastric artery } \\
\text { ligation }\end{array}$ & 9 & $8(8 \%)$ & $0.5 \%)$ & $\mathrm{P}<0.05$ \\
\hline Urinary system injury & 3 & $3(3 \%)$ & $0(0 \%)$ & $\mathrm{P}<0.05$ \\
\hline
\end{tabular}

Table - 3 Neonatal Complications

\begin{tabular}{|l|l|l|l|}
\hline & $\begin{array}{l}\text { Caesarean section in the second stage } \\
\text { of labour }(\mathrm{n}=100)(\%)\end{array}$ & $\begin{array}{l}\text { Caesarean section in the first } \\
\text { stage of labour }(\mathrm{n}=200)(\%)\end{array}$ & P Value \\
\hline Neonatal Trauma & $5(5 \%)$ & $1(0.5 \%)$ & $\mathrm{P}<0.05)$ \\
\hline Low five minute APGAR $(\leq 3)$ & $9(9 \%)$ & $2(1 \%)$ & $\mathrm{NS}$ \\
\hline Requirement for NICU & $12(12 \%)$ & $3(1.5 \%)$ & $\mathrm{P}<0.05)$ \\
\hline
\end{tabular}

\section{References}

[1]. Dumont, L. de Bernis, M. H. Bouvier-Colle, and G. Breart, "Caesarean section rate for maternal indication in sub-Saharan Africa: a systematic review," The Lancet, vol. 358, no. 9290, pp. 1328-1333, 2001.

[2]. S. F. Murray and F. S. Pradenas, "Health sector reform and rise of caesarean birth in Chile," The Lancet, vol. 349, no. 9044, p. 64,1997.

[3]. M. Pai, P. Sundaram, K. K. Radhakrishnan, K. Thomas, and J. P. Muliyil, "A high rate of Caesarean sections in an affluent section of Chennai: is it cause for concern?" National Medical Journal of India, vol. 12, no. 4, pp. 156-158,1999.

[4]. Allen VM, O'Connell CM, Basket! TF. Maternal morbidity associated with cesarean delivery without labor compared with spontaneous onset of labor at term. Obstet Gynecol 2003;102:477-482.

[5]. S. Gifford, S. C. Morton, M. Fiske, J. Keesey, E. Keeler, and K. L. Kahn, "Lack of progress in labor as a reason for cesarean," Obstetrics and Gynecology, vol. 95, no. 4, pp. 589-595,2000.

[6]. S. L. Seal, G. Kamilya, J. Mukherji, S. K. Bhattacharyya, A. De, and A. Hazra, "Outcome in second- versus first-stage cesarean delivery in a teaching institution in Eastern India," American Journal of Perinatology, vol. 27, no. 6, pp. 507-512, 2010.

[7]. Fasubaa OB, Ezechi OC, Orji EO, et al. Delivery of the impacted head of the fetus at caesarean section after prolonged obstructed labour: a randomized comparative study of two methods. J Obstet Gynaecol 2002;22:375-378.

[8]. K.C. Winovitch, D. A. Wing, D. C. Lagrew, and J. FI. Chung, "The risk of acute neonatal morbidities in the delivery room after primary cesarean at term: influence of labor and stage," American Journal of Perinatology, vol. 26, no. 8, pp. 545-551, 2009.

[9]. V.M. Allen, C. M. O'Connell, and T. F. Baskett, "Maternal and perinatal morbidity of caesarean delivery at full cervical dilatation compared with caesarean delivery in the first stage of labour," BJOG, vol. 112, no. 7, pp. 986-990,2005.

[10]. W.R. Cohen, "Influence of the duration of second stage labor on perinatal outcome and puerperal morbidity," Obstetrics and Gynecology, vol. 49, no. 3, pp. 266-269, 1977.

[11]. L.M. Heilman and H. Prystowsky, "The duration of the second stage of labor," American Journal of Obstetrics and Gynecolog, vol. 63, pp. 1223-1233, 1952 .

[12]. S. M. Menticoglou, F. Manning, C. Harman, and I. Morrison, "Perinatal outcome in relation to second-stage duration," American Journal of Obstetrics and Gynecology, vol. 173, no. 3 I, pp. 906-912,1995.

[13]. X.Chang, P. Chedraui, M. G. Ross, L. Hidalgo, and J. Penafiel, "Vacuum assisted delivery in Ecuador for prolonged second stage of labor: maternal-neonatal outcome," Journal of Maternal-Fetal and Neonatal Medicine, vol. 20, no. 5, pp. 381-384,2007.

[14]. L.Cebekulu and E. J. Buchmann, "Complications associated with cesarean section in the second stage of labor," International Journal of Gynecology and Obstetrics, vol. 95, no. 2, pp. 110-114, 2006.

[15]. J. M. Alexander, K. J. Leveno, D. J. Rouse, M. B. Landon, and S. Gilbert, "Comparison of maternal and infant outcomes from primary cesarean delivery during the second compared with first stage of labor," Obstetrics and Gynecology, vol. 109, no. 4, pp. $917-921,2007$ 